\title{
Cultura escrita, oralidade e gênero em conventos portugueses (séculos XVII e XVIII)*
}

Ligia Bellini

"A palavra é disfarce de uma coisa mais grave..."

Adélia Prado

$\mathrm{O}$ artigo aborda formatos e usos da escrita em mosteiros femininos e masculinos, no Portugal dos séculos XVII e XVIII, buscando explorar significados particulares do domínio de técnicas escriturais. Neste sentido, procura adaptar, à especificidade do contexto analisado, sugestões metodológicas dos estudos sobre as implicações do letramento e seus vínculos com a esfera da oralidade, noutros universos histórico-sociais. Palavras-chave: Cultura letrada; oralidade; universo monástico português.

Literate culture, orality and gender in Portuguese convents (Seventeenth and eighteenth centuries)

"Words disguise more serious issues ..."

Adélia Prado

This article is concerned with formats and uses of writing in female and male monasteries, in seventeenth and eighteenth-century Portugal. It explores the particular

\footnotetext{
* Artigo recebido em junho de 2009 e aprovado para publicação em outubro de 2009. O presente artigo é resultado de investigação apoiada pelo $\mathrm{CNPq}$, com bolsa de produtividade em pesquisa.

** Doutora em História pela Universidade de Essex, Reino Unido. É professora da Universidade Federal da Bahia. E-mail: ligiabellini@uol.com.br
} 
meanings of literacy. In order to do this, it attempts to adapt methodological suggestions from studies on the implications of the introduction of literacy, and its links with the universe of orality in different societies, to the specificities of the historical setting that it analyzes.

Keywords: Literacy; orality; Portuguese monastic milieu.

\section{Culture lettrée, oralité et genre dans des couvents portugais (XVIIe et XVIIIle siècles)}

L'article porte sur des formes et des usages de l'écrit dans des monastères féminins et masculins portugais des XVIIe et XVIIIe siècles et essaye d'explorer certains caractères particuliers dans le domaine des techniques de l'écriture. Dans ce sens, on cherche à adapter à la spécificité du contexte analysé quelques suggestions méthodologiques empruntées aux études sur les implications de l'écrit et de ses liens avec la sphère de l'oralité dans d'autres champs historico-sociaux.

Mots-clés: Culture lettrée; oralité; univers monastique portugais.

Em sua discussão sobre possibilidades de abordagem do tema do impacto do letramento nas sociedades, Rosalind Thomas observa que este é muitas vezes considerado como "o catalisador universal", apontando que "o economista o vincula ao progresso econômico; o historiador das ideias, à preeminência intelectual; o antropólogo, à transição da sociedade primitiva para a avançada; o historiador do nacionalismo, ao desenvolvimento do Estado-nação". Thomas argumenta que é necessário ao menos pôr em questão a frequência com que esses efeitos podem ocorrer. Seguindo proposta de Brian Street, a autora classifica os estudos sobre o assunto em duas correntes principais. Uma primeira, que congrega as investigações pioneiras sobre processos relacionados à introdução da escrita alfabética, em especial na Grécia antiga, postula a existência de amplas implicações culturais da emergência da escrita. No caso da Grécia, associa-se à escrita o florescimento do pensamento racional, da filosofia, da historiografia, da democracia. Outra corrente propõe que os efeitos deste fenômeno são historicamente específicos e que, desta forma, só podem ser compreendidos por meio de estudos detalhados de trajetórias e configurações particulares. Posicionando-se junto a esta última tendência, Thomas chama atenção para o fato de que o letramento não constitui uma habilidade isolada, com usos predeterminados e previsíveis, mas que, ao 
contrário, interage com características culturais já instaladas e responde a circunstâncias específicas. ${ }^{1}$

Usos simbólicos ou não documentários da escrita constituem exemplos de aspectos que não se coadunam com as expectativas de uma concepção funcional e racionalista, de acordo com a qual a escrita serviria principalmente para armazenar e comunicar informações, ou mais genericamente para veicular o pensamento racional. Entre tais usos, incluem-se aqueles em que ela desempenha primordialmente uma função visual, estética, como adorno de um objeto, ou é utilizada em manipulações mágicas e como monumento, casos em que importa menos o conteúdo que a existência ou presença em si do texto. ${ }^{2}$ Com respeito especificamente a Portugal no século XVII, Rita Marquilhas analisa textos tidos como dotados de poderes mágicos ou sagrados, como aqueles inscritos em amuletos e talismãs, as cartas de tocar, e a literatura religiosa de uso comum, a exemplo dos livros de horas e dramas sacros. Esta autora observa que a disseminação da leitura e da escrita na época moderna não implicou que um caráter mágico ou sagrado deixasse de ser atribuído a certos textos compostos principalmente com outros objetivos, ou resultou no desaparecimento dos grafismos mágicos. Ao contrário, ao possibilitar uma maior aproximação com eles, contribuiu para integrar novas formas comunicativas escritas ao universo da magia mais antigo. ${ }^{3}$

Estas e outras ideias exploradas adiante, neste artigo, têm relevância para os estudos que abordam os vínculos entre empoderamento de grupos sociais subalternos e práticas da escrita. No que tange às relações de gênero em particular, o domínio das letras foi, de modo geral, considerado um índice de emancipação feminina, ${ }^{4}$ uma associação que tem sua razão de ser, dado que a escuta direta da voz das mulheres depende do seu acesso a meios de expressão, entre os quais o de maior importância para os historiadores é a escrita. Em relação ao mundo português do Antigo Regime, análises da literatura conventual de autoria de mulheres indicam que essa literatura era

\footnotetext{
${ }^{1}$ Rosalind Thomas, Letramento e oralidade na Grécia Antiga, São Paulo, Odysseus Editora, 2005, p. 21-40, citação p. 27.

2 Thomas, Letramento e oralidade [...], capítulo 5.

${ }^{3}$ Rita Marquilhas, “Orientación mágica del texto escrito”, in Antonio Castillo (org.), Escribir y leer en el siglo de Cervantes, Barcelona, Gedisa, 1999, p. 111-128.

${ }^{4}$ Ver, por exemplo, Margaret L. King, A Mulher no Renascimento, Lisboa, Editorial Presença, 1994, p. 180ss.; e Georges Duby e Michelle Perrot, "Escrever a história das mulheres", in Duby e Perrot (dir.), História das mulheres no Ocidente, Porto, Edições Afrontamento, 1993, p. 7-18.
} 
parte integrante de uma rede de negociações entre os mosteiros e a corte, que incluía também o ingresso, neles, de religiosas oriundas de famílias nobres, manifestações de fidelidade política por parte das freiras, e favores e doações da família real às casas monásticas, entre outras práticas. ${ }^{5}$ Noutras palavras, os escritos constituíam vias pelas quais as religiosas negociavam e adquiriam prestígio e benesses para si e para as comunidades às quais pertenciam. ${ }^{6}$

Diversos autores postulam que o ingresso de mulheres nos claustros em geral lhes permitia um acesso à cultura letrada que, de outro modo, não teriam. Apesar de, no período moderno, o papel dos mosteiros no florescimento intelectual ter se tornado menos relevante que o das universidades, eles continuaram constituindo, junto com a corte, lugar importante de treinamento nas letras para o elemento feminino. Esta formação, em conjunto com o fato de que as monjas viviam mais resguardadas das pressões e obrigações do mundo

\footnotetext{
${ }^{5}$ Neste trabalho os termos "mosteiro", "monastério" e "convento" (e, por extensão, os adjetivos deles derivados) são usados como sinônimos, nas acepções gerais modernamente encontradas nos dicionários, quais sejam, a de habitação de uma comunidade religiosa, conjunto dos(as) religiosos(as) que nela residem e vida religiosa que aí se leva. Textos do período estudado fazem distinção entre "mosteiro" - estabelecimento onde os(as) religiosos(as) vivem isolados(as) do restante do mundo, e portanto sempre aplicável às comunidades femininas, para as quais a clausura é regra - e "convento" - cujo significado remete à ideia de vida em conjunto, não necessariamente em isolamento. Frei Manoel da Esperança, na primeira parte da sua Historia Serafica da Ordem dos Frades Menores de S. Francisco na Provincia de Portugal, afirma que o uso dos vocábulos "mosteiro" para freiras e "convento" para frades era o que se encontrava nos anais da ordem e nas bulas papais. Ver Manoel da Esperança, "Declarações importantes aos que lerem esta obra", in Esperança, Historia Serafica da Ordem dos Frades Menores de S. Francisco na Provincia de Portugal, Lisboa, Oficina Craesbeeckiana, 2 vols., 1656 e 1666, respectivamente, páginas iniciais, s/p. Segundo Kate Lowe, do ponto de vista da terminologia eclesiástica correta, mosteiros são habitados por membros masculinos e femininos das ordens monásticas, isto é, Beneditinos, Camaldolenses, Vallombrosianos, Cistercienses etc.; membros das ordens canônicas; e membros das ordens segundas das ordens mendicantes, como as Agostinianas, Clarissas, Dominicanas etc. Conventos, por seu turno, são habitados por membros masculinos das ordens mendicantes, como os Dominicanos e Franciscanos; e por membros do clero regular, como os Jesuítas. Kate J. P. Lowe, Nuns' chronicles and convent culture in Renaissance and Counter-Reformation Italy, Cambridge, Cambridge University Press, 2003, p. 5.

${ }^{6}$ Isabel Morujão, "Entre o convento e a corte: algumas reflexões em torno da obra poética de Soror Tomásia Caetana de Santa Maria", Revista da Faculdade de Letras - Línguas e Literaturas, Anexo V, Porto, 1993, p. 123-141, p. 126-127; Moreno Laborda Pacheco, "Vivência religiosa, escrita e poder em conventos franciscanos femininos. Portugal, séculos XVII e XVIII", Monografia de conclusão do Bacharelado em História, Universidade Federal da Bahia, 2007.
} 
secular, em especial as relativas ao casamento, teria ensejado certa autonomia e mesmo autoridade para algumas delas. ${ }^{7}$

No entanto, se aceitarmos a validade da proposta de Thomas, é necessário investigar os limites da aquisição de poder e da mudança viabilizadas pelo domínio de técnicas escriturais, e inquirir sobre seus significados e ligação com outros fatores numa situação histórica particular. Um primeiro aspecto a ser considerado neste sentido diz respeito à interferência de diretores e conselheiros do sexo masculino nas atividades femininas relacionadas à leitura e à escrita, nos conventos. As freiras estavam submetidas a membros masculinos de sua ordem ou de outras, assim como do clero secular. No século XVII, as seguidoras da Primeira Regra de Santa Clara, por exemplo, deviam obediência aos frades da Ordem Primeira de São Francisco. ${ }^{8}$ Certos documentos ilustram a ascendência de autoridades eclesiásticas sobre práticas de escrita e usos dos textos em mosteiros femininos. As Cartas espirituaes do frei António das Chagas dão testemunho das orientações que dava a religiosas quanto à leitura de textos. ${ }^{9}$ Carta datada de 1652, dirigida pelo provincial da Província dos Algarves da Ordem Franciscana em Portugal, frei Acúrcio de São Pedro, à abadessa do Convento de Jesus de Setúbal, também evidencia a influência de membros do clero na relação das freiras com a escrita e a leitura. Nela, o frade, além de comunicar a impossibilidade de uma obra sobre a história e outros assuntos relativos ao convento ${ }^{10}$ ser publicada, recomenda onde e em quais circunstâncias o manuscrito deveria ser guardado e reproduzido, e como

${ }^{7}$ Lina Eckenstein, Woman under monasticism, Cambridge, Cambridge University Press, 1896, p. 354ss.; King, A Mulher no Renascimento, p. 103ss.; Merry Wiesner-Hanks (ed.), Convents confront the Reformation: Catholic and Protestant nuns in Germany, Milwaukee, Marquette University Press, 1998, p. 12; Antonio Castillo Gómez, "La pluma de Dios. María de Ágreda y la literatura autorizada”, Via Spiritus, 6, 1999, p. 103-119, p. 103; María del Mar Graña Cid, "Palabra escrita y experiencia femenina en el siglo XVI", in Castillo (org.), Escribir y leer en el siglo de Cervantes, p. 211-242, p. 225.

${ }^{8}$ Constituiçoens geraes pera todas as freiras, e religiosas sojeitas à obediencia da Ordem de N.P.S. Francisco, nesta Familia Cismontana. De novo recopiladas das antigas; e acrescentadas com acordo, consentimento, \& appprovação do Capitulo Geral, celebrado em Roma a 11 de Junho de 1639, Lisboa, Officina de Miguel Deslandes, 1693, p. 2-3.

${ }^{9}$ José Adriano de Freitas Carvalho, "Do recomendado ao lido. Direcção espiritual e prática de leitura entre franciscanas e clarissas em Portugal no século XVII", Via Spiritus, 4, 1997, p. 7-56, p. 15-32.

${ }^{10}$ Leonor de São João, Tratado da antiga e coriosa fundaçaõ do Convento de Jesu de Setuval, O Primeiro, que ouve, e se fundou neste Reyno de Portugal de Religiosas capuchas, chamadas as Senhoras Pobres da $1^{a}$ Regra de Santa Clara, 1630, [MS]. 
deveria ser usado. ${ }^{11}$ Deve-se considerar ainda o que estipulavam, sobre a matéria, as regras e constituições. As Constituiçoens geraes pera todas as freiras, e religiosas sojeitas à obediencia da Ordem de N.P.S. Francisco, publicadas em 1693, enfatizam a importância da leitura de "lições espirituais" nas refeições e durante os trabalhos, e de livros "santos, \& devotos", proibindo "com todo o rigor" livros "de comedias, nem outros quaesquer, que expressa, ou tacitamente contenhaõ vaidades, ou carnalidades, ou cousas de pessoas mundanas". ${ }^{12}$ Estipulam também o que devia ser registrado por escrito - "a fundaçaõ, \& padroado do Convento, os legados, \& lembranças, que em cada hum ouver", não esquecendo de mencionar "toda a fazenda que tem, assim de juros, censos, herdades, \& casas, \& outros quaesquer bens de raiz [...] privilegios, \& Provisoens Reaes". ${ }^{13}$ Tanto as constituições quanto as regras determinam quantas vezes e em que tempos estas deveriam ser relidas em comunidade..$^{14}$

No que respeita à elaboração de crônicas conventuais em particular, gênero que recebe foco especial neste trabalho, sabe-se, em primeiro lugar, que eram escritas por dever de ofício. Havia um plano geral do que deveria ser registrado. ${ }^{15} \mathrm{O}$ ofício de escritor / escritora era rotativo e as irmãs ou frades que o desempenhavam eram escolhidos pelos superiores de acordo com suas habilidades ou perfil. Estes elementos representam restrições a uma tentativa de tratar suas produções como obras de autor, no sentido que a concepção de autoria adquiriu a partir da segunda metade do século XVIII, associada à ideia de criação original, a qual carregaria a marca exclusiva do seu criador, e também relacionada à ideia de propriedade. ${ }^{16}$ Mas pode-se argumentar que, se as determinações acima ocorriam na maior parte dos casos, então as diferenças

\footnotetext{
${ }^{11}$ Arquivo Distrital de Leiria, Fundo Mosteiro de Jesus de Setúbal, Cartas, documento 2. Cópia deste documento foi gentilmente cedida por Moreno Laborda Pacheco.

${ }^{12}$ Constituiçoens [...], cap. IV, p. 91-92; e cap. III, § 2, p. 84.

${ }^{13}$ Constituiçoens [...], cap. XIV, p. 139-140.

${ }^{14}$ Constituiçoens [...], cap. XV, p. 146; na mesma edição, Segunda Regra de Santa Clara, cap. XXVI, p. 57.

${ }^{15}$ Uma evidência disto é apresentada por Moreno Pacheco. Pacheco cita texto manuscrito, o Memorial da Santa Província, no qual se encontram anotações do seu autor, frei Rodrigo de S. Thiago, sob o título "Lembrança das notícias que se devem indagar para a Chronica", aparentemente feitas no sentido de orientar a composição do Memorial. Os tópicos listados correspondem aproximadamente aos abordados nas crônicas do período. Moreno Laborda Pacheco, "Quando as freiras faziam história: crônicas conventuais, autoria feminina e poder em Portugal no século XVII”, Anais do Simpósio Nacional de História - ANPUH, História e Ética, Julho 2009, p. 6-7.

${ }^{16}$ Ver Mark Rose, "The author as proprietor: Donaldson v. Becket and the genealogy of modern authorship", Representations, 23, Berkeley, 1988, p. 51-85.
} 
entre as crônicas indicam diferenças entre autores(as), casas monásticas, ordens religiosas, finalidades e usos dos textos. As características gerais do gênero e as regras institucionais que determinavam a composição dos escritos não explicam todos os seus aspectos.

Com o objetivo de explorar os significados e particularidades históricas do domínio da escrita, podemos nos valer ainda das reflexões de Roger Chartier sobre o tema e também, ressalvando-se os limites e nuances relacionados à especificidade dos contextos históricos e às crenças variadas sobre a escrita e seus usos, de ideias e sugestões metodológicas surgidas no âmbito dos primeiros estudos sobre as implicações do letramento e suas relações com a esfera da oralidade.

Uma possibilidade de abordagem associa-se à questão das diferenças entre procedimentos linguísticos orais e escritos, objeto do estudo clássico de Walter J. Ong. ${ }^{17} \mathrm{O}$ autor examina modos específicos de pensar e sua expressão em formas linguísticas em tradições puramente ou predominantemente orais, comparando-as com tais formas em tradições escritas. Analisar textos do ponto de vista destas diferentes formas pode contribuir para iluminar modalidades particulares de escrita, algumas delas resultantes de uma cultura com um importante componente oral. Neste sentido, certos textos talvez não devam ser considerados simplesmente como um indício da inserção dos seus autores no universo da cultura letrada, sem ter em conta que, a par de constituírem evidência de um domínio das letras, tais escritos foram elaborados de acordo com modos de pensar e de se exprimir típicos de culturas orais.

Ong observa que um aspecto central do pensamento e sua expressão em culturas orais é seu cunho mnemônico e formular. Se, em determinada cultura, a escrita não tem um papel importante na preservação de coisas pensadas, então estas, para serem preservadas, têm que ser associadas a elementos que podem ser mais facilmente retidos na memória, como fórmulas, provérbios e ritmos indutores de memorização oral. Além disto, pensamento e expressão numa cultura com um elevado resíduo oral tendem a ser aditivos, em vez de subordinativos. O discurso escrito, no qual o significado é mais dependente da estrutura linguística, tem mais condições de desenvolver uma gramática elaborada que o oral. Este último é ainda agregativo, em vez de analítico, o que deriva da sua tendência a usar fórmulas. A partir do momento em que deter-

${ }_{17}$ Walter J. Ong, Orality and literacy: the technologizing of the word, Londres e New York, Routledge, 2002. 
minada expressão formular tenha sido cristalizada, ela tende a ser mantida, em lugar de se questionar os limites do seu caráter de verdade. O pensamento em tradições predominantemente orais tende também a ser mais redundante porque, na ausência da escrita para estabelecer uma linha de continuidade fora da mente, é a repetição do que já foi dito que mantém a continuidade para quem fala e quem escuta. Tende ainda a ser mais tradicionalista. $\mathrm{O}$ conhecimento, numa cultura não letrada, precisa ser repetido para não ser esquecido, o que, de acordo com Ong, contribui para a emergência de um modo de pensar mais conservador, que inibe a experimentação intelectual. Em conformidade com os mecanismos acima, em culturas marcadas pela oralidade, o pensamento e sua expressão em formas linguísticas tendem a ter como referência central a experiência humana imediata, e a ter um tom agonístico, participativo e fundado na empatia, em vez de buscar um distanciamento em relação a seus objetos. As ideias são, em geral, postas em quadros de referência situacionais ou operacionais que são minimamente abstratos. Ong postula que, embora seja evidente que culturas exclusivamente orais tenham mecanismos próprios de obter e praticar conhecimento, um exame sequencial, classificatório e explanatório de fenômenos só é possível com o uso da leitura e da escrita. ${ }^{18}$

Uma ilustração das concepções acima nos é dada pela análise de Chartier do conto narrado por Sancho a Dom Quixote, no capítulo XX da primeira parte do romance de Cervantes. Na narrativa de Sancho, formado no âmbito da oralidade, multiplicam-se as retomadas, os retrocessos, as interrupções constantes para fazer alusão à situação em que estavam naquele momento. Dom Quixote, o leitor, por sua vez, esperava "uma narrativa linear, sem retomadas, sem interrupções, sem digressões" ${ }^{19}$

Em consonância com as idéias de Ong, Eric Havelock, em seu estudo sobre as implicações da introdução da escrita alfabética na Grécia antiga, afirma que "se fosse possível designar o novo discurso por uma palavra nova, o termo seria: conceitual". O autor observa, no processo, a tendência crescente de "enunciar proposições, em lugar de descrever eventos". Havelock argumenta, além disto, que a capacitação de uma cultura para ler, escrever e lidar com conceitos depende da iniciação nas letras no nível primário de escolaridade. Segundo ele, na literatura grega até Platão, verifica-se uma "parceria" ou uma "tensão

\footnotetext{
${ }^{18}$ Ong, Orality and literacy, p. 8-9 e 31-57.

${ }^{19}$ Roger Chartier, "História e literatura", in Chartier, À beira da falésia. A história entre certezas e inquietude, Porto Alegre, Editora Universidade / UFRGS, 2002, p. 255-271, p. 260-261.
} 
dinâmica" entre oral e escrito, com o último apresentando características dos princípios de composição - e do pensamento - não letrados. ${ }^{20}$

Quando se fala de oralidade e letramento, é necessário ter em conta que, no mais das vezes, não se trata de domínios estanques e "puros". Paul Zumthor, em seu estudo sobre a função poética da voz nas obras "literárias" medievais, nota a existência de três tipos de oralidade, correspondentes, segundo ele, "a três situações de cultura". Entre estes tipos, apenas um, encontrado nas sociedades em que inexiste um sistema de simbolização gráfica, não envolve qualquer contato com a escritura. As outras duas formas de oralidade têm como característica comum o fato de coexistirem com a escritura. O autor as denomina, de acordo com a influência da escrita nelas, de "oralidade mista" e "oralidade segunda". Na primeira, a influência do escrito seria "externa, parcial e atrasada". A oralidade segunda seria aquela que emerge em uma cultura "letrada", "na qual toda expressão é marcada mais ou menos pela presença da escrita". ${ }^{21}$

Enfocando-se, no sentido inverso, marcas de formas tipicamente orais de pensamento na expressão escrita, pode-se retomar ideias de Ong quando este autor nota que as primeiras, estando profundamente instaladas numa cultura e na mente dos indivíduos, não desaparecem subitamente com a introdução do letramento. Em sua formulação, somente muito gradualmente a escrita se torna composição escrita. Uma cultura oral, em geral, não lida com elementos como categorização abstrata, processos lógicos formais, definições, ou mesmo descrições e autoanálise extensivas, todos derivados do pensamento produzido em estreita ligação com a escrita. ${ }^{22}$

Zumthor investiga, na literatura medieval, o que ele denomina de "índices de oralidade": "tudo o que, no interior de um texto, informa-nos sobre a intervenção da voz humana em sua publicação - quer dizer, na mutação pela qual o texto passou, uma ou mais vezes, de um estado virtual à atualidade e existiu na atenção e na memória de certo número de indivíduos”. O índice pode ser uma notação musical; a alusão a acompanhamento instrumental; o recurso a verbos como dizer, falar, contar, frequentemente acompanhados, do ponto de vista da recepção, por termos como ouvir ou escutar. ${ }^{23}$

${ }^{20}$ Eric A. Havelock, A revolução da escrita na Grécia e suas consequências culturais, São Paulo, Editora UNESP; Rio de Janeiro, Paz e Terra, 1996, passim, citações p. 16-17, grifo do autor. ${ }^{21}$ Paul Zumthor, A letra e a voz: a "literatura" medieval, São Paulo, Companhia das Letras, 1993, p. 18-19.

${ }^{22} \mathrm{Ong}$, Orality and literacy, p. 26 e 54-55.

${ }^{23}$ Zumthor, A letra e a voz, p. 35, grifo do autor. 
No presente artigo, que investiga um período caracterizado pela presença consolidada da escritura, interessam centralmente dispositivos que sugerem que os textos eram dirigidos a um duplo público - que lia e que estava acostumado a ler em voz alta e a ouvir ler. Referindo-se a práticas da leitura e da escrita em conventos e recolhimentos femininos em Portugal e no Brasil, nos séculos XVII e XVIII, Leila Algranti chama atenção para o domínio desigual da leitura, neles. Algumas religiosas podiam ser capazes apenas de acompanhar a leitura coletiva no coro ou, "dado o caráter repetitivo da leitura dos textos sagrados [...] podiam declamá-los por memorização - 'reconhecendo' o texto e não exatamente lendo-o [...]". ${ }^{24} \mathrm{O}$ fato de que nem todas as freiras estavam aptas para ler as mesmas obras, em particular as que exigiam "uma atenção directa, pessoal e constante, ao texto", é também apontado por José Adriano de Freitas Carvalho, em seu estudo sobre leitura entre franciscanas em Portugal no século XVII. ${ }^{25}$ A leitura coletiva possibilitava o contato com os conteúdos dos textos para as que não sabiam ler. Possibilitava, além disto, que a escolhida como leitora se aperfeiçoasse na prática, pois nem sempre era suficientemente fluente para que não necessitasse ler os textos em voz alta. A propósito de certos textos produzidos na Europa nos séculos XVI e XVII, Chartier nota que "feitos para serem recitados ou lidos em voz alta e compartilhados em uma escuta coletiva, investidos de uma função ritual, pensados como máquinas de produzir efeitos, eles obedecem às leis próprias da performance ou da efetuação oral e comunitária". ${ }^{26}$

Entre os dispositivos que podem ser considerados como os que atribuem aos textos um público que lê em voz alta e que escuta ler, estão a divisão em unidades pequenas / capítulos curtos, e a composição incluindo múltiplos episódios autônomos e formas simplificadas de intriga. Outro aspecto que denuncia a orientação dos textos neste sentido é a enunciação fictícia criada, a exemplo da reunião de diversos narradores no enredo. Desta forma, o provérbio, o diálogo, além de, evidentemente, o teatro e o jogral, são gêneros mais diretamente associados à oralidade. ${ }^{27}$ Mas neste artigo procurar-se-á também, na medida do possível, identificar índices de oralidade na forma mesma pela qual o pensamento é expresso.

${ }^{24}$ Leila Mezan Algranti, Livros de devoção, atos de censura: ensaios de história do livro e da leitura na América portuguesa (1750-1821), São Paulo, Editora Hucitec; FAPESP, 2004, p. 55-56.

${ }^{25}$ Carvalho, "Do recomendado ao lido [...]", p. 15.

${ }^{26}$ Chartier, "História e literatura", p. 260.

${ }^{27}$ Chartier, "História e literatura", p. 260-270. 
Crônicas conventuais referentes a casas monásticas e a uma província como um todo, do ramo franciscano, escritas no século XVIII num intervalo de aproximadamente quarenta anos, podem ser analisadas comparativamente com base em algumas das ideias mencionadas acima. O Espelho de penitentes, e chronica da Provincia de Santa Maria da Arrabida (1728), de Antonio da Piedade, ${ }^{28}$ é, como indica o título, uma narrativa dos acontecimentos considerados mais relevantes na história da província da Arrábida, desde seus inícios, em 1539, até as primeiras décadas do século XVII. No tom apologético e mitificante característico do gênero, versa sobre os vários conventos pertencentes à província, inclusive missões no ultramar, ${ }^{29}$ exaltando os ideais de perfeição evangélica da ordem, as virtudes de seus membros, assim como a devoção dos portugueses, em especial dos nobres, para com eles. A obra foi mais tarde complementada por outra com o mesmo título e propósitos semelhantes, de autoria de Joseph de Jesus Maria, publicada em 1737. ${ }^{30}$ Uma crônica de autoria feminina, intitulada Jardim do ceo, plantado no Convento de Nossa Senhora da Conceição da cidade de Braga, da Madre Maria Benta do Ceo (publicada em 1766), ${ }^{31}$ trata de uma comunidade de concepcionistas, de 1629 até $1764 .{ }^{32}$ Embora contenha relato inicial sobre a criação da ordem e do mosteiro, assim como adendos finais, a maior parte do livro consiste nas biografias, também em tom encomiástico, de vinte mulheres ali ingressadas (uma delas ingressada no Mosteiro das Capuchas Descalças da Vila de Chaves), com cada capítulo dedicado a uma religiosa.

No prólogo da sua obra, Antonio da Piedade declara que esta foi composta respondendo a designação de prelados da ordem, no sentido de que

\footnotetext{
${ }^{28}$ Antonio da Piedade, Espelho de penitentes, e chronica da Provincia de Santa Maria da Arrabida da regular, e mais estreita observancia da Ordem do Serafico Patriarca S. Francisco, no Instituto Capucho, tomo I, Lisboa, Joseph Antonio da Sylva, Impressor da Academia Real, 1728. ${ }^{29}$ Frei Manoel da Esperança informa que, à época em que compôs sua Historia, a província da Arrábida incluía dezenove conventos e uma enfermaria no Hospital Real de Lisboa. Esperança, Historia Serafica[...],1656, p. 15-16.

${ }^{30}$ Joseph de Jesus Maria, Espelho de penitentes, e chronica de Santa Maria da Arrabida em que se manifestam as vidas de muntos santos varoens de abalizadas virtudes, e outros que pella verdade da Fé sacrificàraõ as vidas destribuidas por todos os dias do anno, Lisboa Occidental, Officina de Joseph Antonio da Sylva, Impressor da Academia Real, 1737.

${ }^{31}$ Maria Benta do Ceo, Jardim do ceo, plantado no Convento de Nossa Senhora da Conceiçã̃ da cidade de Braga, Em que se trata das Memorias da Fundaçã̃ deste primeiro Convento do Reyno dedicado à Conceiçaõ purissima de nossa Senhora [...], Lisboa, Officina de Manoel Coelho Amado, 1766.

${ }^{32}$ A Ordem da Conceição, criada em Toledo em 1489, em que pese tenha tido diferentes regras no decorrer da sua existência, seguiu predominantemente orientação clariana, em especial a chamada Segunda Regra, promulgada pelo Papa Urbano IV em 1263.
} 
a província tivesse uma "história" de acordo com as regras que regiam este gênero. Citando Cícero, o autor afirma que "para a fabrica da Historia duas cousas saõ necessarias, a primeira indagar as noticias, e a segunda eleger o modo com que se devem compor, e explanar". Confessando que pouco encontrou nos arquivos nos quais buscou documentos, Antonio da Piedade declara que garimpou as notícias de que trata nos trabalhos de cronistas que o antecederam, mas as "acomodou" ao seu próprio estilo e averiguou detalhes. Critica crônica anterior, escrita pelo Frei Luiz da Ascenção sobre a província e datada de 1650, pela forma como este estruturou a obra e pelas digressões nela contidas. Piedade inclusive pede desculpas aos seus leitores pelas próprias digressões, no Espelho de penitentes. Concepções similares sobre as características esperadas do gênero também se encontram nos pareceres de religiosos consultados sobre a propriedade da publicação do livro, reproduzidos no início deste. Frei Boaventura de S. João [“Giaõ”] faz menção à prática, na obra, das "leys da Historia", "na fidelidade da narraçaõ, na ordem dos successos, na pontualidade dos tempos, dos lugares, e das pessoas, na ponderaçaõ dos motivos, e causas de tudo o que se obrou, ou omittio". Refere-se também ao estilo, qualificado como "grave, e sublime, claro, e elegante, natural sem artificio, e culto sem pompa de voos, e affectação de palavras".

No entanto, tomando-se como referência concepções estabelecidas no meio historiográfico moderno, as quais discriminam três tipos básicos de representação histórica, verifica-se que o Espelho de penitentes seria melhor qualificado como crônica, ao invés de história. É relevante explorar brevemente aqui o elemento que ocupa lugar central como característica distintiva entre estes tipos de representação, qual seja, seu grau de "narratividade". Como observa Hayden White, num texto que aspire a ser considerado propriamente histórico, os eventos devem ser narrados, quer dizer, "revelados como possuindo uma estrutura, uma ordem de significado, que eles não possuiriam se apresentados como mera sequência ". Nos anais, sendo estes apenas uma lista de eventos ordenados em sequência cronológica, os elementos narrativos estariam inteiramente ausentes, o que já não ocorre na crônica, que "aspira à narratividade", apresentando-se na forma de uma história contada. Entretanto, falta a esta última o "fechamento" narrativo. A história contada na crônica não tem conclusão, desenrola-se de um começo até o presente do cronista, onde simplesmente termina. White trata os anais e a crônica como formas diferentes 
de representação histórica, não como histórias imperfeitas. ${ }^{33}$ Kate Lowe, em seu estudo sobre crônicas conventuais femininas na Itália moderna, põe em questão a utilidade de se diferenciar histórias e crônicas, no período. Lowe aponta que era comum, entre os membros de ordens religiosas, chamar de crônicas as histórias de suas instituições, embora, em certos momentos, façam referência às suas crônicas como histórias, o que indica que tinham as duas categorias de escrita como inseparáveis. ${ }^{34}$ Mas a ideia de que seriam equivalentes e intercambiáveis não parece ser a sustentada pelos autores setecentistas referidos acima, em cujas formulações observa-se uma valorização da história como superior às demais formas, embora também chamem de história um texto que, com base nos critérios convencionais de distinção entre os três gêneros, deveria ser classificado como crônica. Uma crônica que se interrompe não no presente do autor, mas nas primeiras décadas do século XVII.

O Espelho de penitentes estrutura-se em cinco livros, totalizando 972 páginas em 166 capítulos que se desenrolam seguindo aproximadamente uma ordem cronológica. Em certas passagens, conforme o próprio autor nota, há de fato digressões, retornos na cronologia e longas caracterizações de certos personagens, em especial patronos nobres - e.g. o Duque de Aveiro, o Infante D. Luis (1506-) e o Cardeal D. Henrique (1512-1580), cujas ações são referidas com frequência - ou membros da comunidade que se destacaram por suas virtudes $-e . g$. o fundador da província, Frei Martinho de Santa Maria (†1546) e São Pedro de Alcântara (1499-1562), entre outros. Mas diversos trechos indicam que houve um plano para a estrutura geral da obra, ou ao menos que o autor estava em controle do longo texto como um todo, visto que remete a outras passagens em que certos temas seriam retomados, ou mostra estar ciente de que já afirmou ou tratou de algo anteriormente. Os parágrafos são numerados, dispositivo que serve de referência para o índice de assuntos incluído no final do livro.

Antonio da Piedade demonstra sua observância do que considera serem os princípios da "fabrica da Historia" ao recorrer, em diversos trechos do livro, a documentos para determinar a veracidade de certos fatos ou para dirimir dúvidas quanto a estes. Há ainda o recurso a uma argumentação fundada em dados cronológicos e a transcrição de fontes documentais.

\footnotetext{
${ }^{33}$ Hayden White, "The Value of Narrativity in the Representation of Reality", Critical Inquiry, vol. 7, no. 1, On Narrative, Chicago, Outono 1980, p. 5-27, citações p. 9.

${ }^{34}$ Lowe, Nuns' chronicles and convent culture in Renaissance and Counter-Reformation Italy, capítulo 1 .
} 
Em conjunto, todos estes elementos sugerem um pensamento e uma composição elaborados em estreita relação com o universo da escrita.

A obra de Joseph de Jesus Maria que dá seguimento à de Antonio da Piedade estrutura-se de forma diferente desta, centrando-se nas biografias dos "varoens santos", organizadas de acordo com os dias do ano em que os biografados faleceram, embora também narre a celebração dos capítulos provinciais, a fundação de novos conventos e mesmo, eventualmente, um conflito entre duas facções rivais da província. Do ponto de vista cronológico, estende-se de 1623 até a época da composição da crônica, "pela ordem dos annos", conforme anuncia o autor no proêmio do livro. A estrutura é predominantemente descritiva e bastante repetitiva, mas, em certas passagens, fica evidente o olhar mais analítico do autor. Um exemplo é a passagem sobre Frei Masseo de São Francisco, porteiro do convento de São Pedro de Alcântara em Lisboa, condenado à perpétua reclusão no convento de Torres Vedras, onde viveu por dez anos antes de morrer em 1714. De acordo com Joseph de Jesus Maria, Frei Masseo, tendo sido apontado pelo Santo Ofício como diretor de consciência de Maria de Jesus, beata penitenciada anteriormente "por embustes, e ficção de revelações", deixou-se persuadir por ela e a tratava com veneração, "sendo ella a que lhe regia as suas acções". Com o evidente propósito de atenuar a culpa do frade, a narrativa de Jesus Maria se desenvolve procurando explicar suas atitudes, com base numa suposta ingenuidade sua, evidenciando como ele havia sido ludibriado pela beata. ${ }^{35}$ Também denotam uma abordagem mais crítica as referências às tentações carnais de alguns dos frades, mesmo que seja para salientar como estes resistiram a elas ou posteriormente retornaram para uma conduta virtuosa. ${ }^{36}$

A edição do Jardim do ceo, de Maria Benta do Ceo, também sugere que o texto foi composto segundo um plano geral previamente definido. Diferentemente de outras crônicas de mosteiros femininos, manuscritas, examinadas adiante, que não eram obras fechadas e podiam ser complementadas/atualizadas por autoras posteriores, o Jardim do ceo se encerra com adendos que lhe servem de fecho - "Advertencias sobre a reza do Coro"; uma discussão sobre a Imaculada Conceição de Maria; e cópia da bula papal que instituiu a ordem - ficando as biografias encerradas na parte central da obra. É provável que a intervenção do editor tenha contribuído para isto, assim como para o

\footnotetext{
${ }^{35}$ Jesus Maria, Espelho de penitentes, e chronica de Santa Maria da Arabida, p. 814-822.

${ }^{36}$ Jesus Maria, Espelho de penitentes, e chronica de Santa Maria da Arabida, p. 107-108; 181.
} 
bem ordenado índice dos capítulos do livro. Mas a publicação se deveu, em alguma medida, aos méritos do texto original. A linguagem é clara e bem articulada, e a estrutura é coerente. Dados relativos às religiosas cujas vidas são narradas - algumas das quais viveram mais de cem anos antes da publicação do livro -, incluindo data e idade de entrada, nomes dos pais, fatos ocorridos durante sua estada no mosteiro e data do falecimento, evidenciam que a autora consultou documentos escritos do arquivo do convento. Na discussão, no capítulo XXX, da Imaculada Conceição de Nossa Senhora, Maria Benta do Ceo, mesmo que provavelmente de segunda mão, cita concepções de Tomás de Aquino (c.1225-1274), Duns Escoto (c.1265-1308), Gregório Magno (c.540604), Bernardo de Claraval (1090-1153), entre outros, assim como excertos das Revelações de Santa Brígida (1303-1373) e bulas de pontífices. ${ }^{37} \mathrm{Na}$ dedicatória do livro ao Arcebispo de Braga, a autora faz menção ao proveito que suas companheiras de claustro poderiam ter com a leitura sobre as trajetórias e atitudes modelares das biografadas, que com o seu exemplo poderiam "incitar as mais a imitallas". ${ }^{38}$ Vê-se aqui o motivo clássico que atravessa, desde a Antiguidade, as discussões sobre a utilidade da escrita da história, de que se pode aprender com ela no presente. A diferença, neste caso, é que as "heroínas", e a própria autora, são freiras. ${ }^{39}$

Entretanto, observa-se também diferenças notáveis entre esta última crônica e as duas referidas anteriormente. O texto de Maria Benta do Ceo é muito menos extenso, tendo 196 páginas incluindo os adendos, sem parágrafos numerados. A diferença quanto à extensão se amplia se considerarmos que foi editado com fonte maior que a das crônicas da Arrábida. Cada notícia sobre o mosteiro e cada biografia constitui uma unidade de conteúdo bem delimitada, independente das demais. Os capítulos não se sucedem seguindo uma ordem cronológica, que acompanhasse a trajetória do convento da Conceição. Os capítulos iniciais sobre os começos da ordem e a fundação da casa (incluindo um sobre a fundação de outras duas casas) são seguidos pela biografia de uma freira que faleceu em 1739 (Custodia Maria do Sacramento), por sua vez seguida da vida de uma ingressada no ano de 1629 (Anna do Salvador). O argumento é simples, relatando episódios associados ao objeto de cada capítulo. Em conjunto, estes elementos remetem aos dispositivos apontados por Chartier, citados

\footnotetext{
${ }^{37}$ Benta do Ceo, Jardim do ceo, p. 179-189.

${ }^{38}$ Benta do Ceo, Jardim do ceo, "Dedicatória a Dom Gaspar", s/p.

${ }^{39}$ Ver, a propósito desta idéia, Lowe, Nuns' chronicles and convent culture in Renaissance and Counter-Reformation Italy, p. 24.
} 
anteriormente, que denunciam a orientação dos textos para a leitura em voz alta e a escuta coletiva compartilhada. As histórias contadas nos em geral breves capítulos do Jardim do ceo, cujo desenvolvimento e epílogo estão inteiramente contidos em cada um dos capítulos, parecem adequar-se melhor que as das crônicas da Arrábida à leitura, por uma das irmãs, para as suas companheiras reunidas. Esta interpretação está de acordo com a hipótese de Lowe, de que a audiência mais óbvia para as crônicas de conventos femininos eram os seus respectivos coletivos. A autora cita evidências, por ela encontradas nos textos manuscritos que estudou, que sugerem que foram escritos para serem lidos em voz alta, possivelmente no refeitório ou no coro. ${ }^{40} \mathrm{~A}$ compreensão aqui aventada sobre o uso coletivo, por meio desta forma de leitura, é também corroborada pela já citada carta do frei Acúrcio de São Pedro à abadessa do Convento de Jesus de Setúbal, na qual o missivista recomenda que o livro sobre a história do convento fosse lido em comunidade. ${ }^{41}$ É relevante notar que este tipo de recepção não implica que os textos não eram, em paralelo, objeto de leitura silenciosa individual. As crônicas eram provavelmente mantidas na biblioteca dos conventos e podiam ser lidas lá também. Além disto, o fato de o Jardim do ceo ter sido publicado em forma impressa, bem como certas passagens do livro, constituem indicação de que era dirigido também a um público de fora. No final da sua discussão sobre a Imaculada Conceição de Nossa Senhora, Maria Benta do Ceo afirma: "parece-nos bem suspender a penna, e sujeitar humildemente naõ só á correcção da santa Madre Igreja quanto havemos dito, senaõ tambem a todo o Varaõ douto, que desapaixonado o ler [...]”. ${ }^{42}$ Também o qualificador do Santo Ofício que concede a licença para publicação faz referência às "Religiosas dos mais Mosteiros" que poderiam beneficiar-se com os exemplos de virtude contidos na obra.

Outro tipo de diferença entre as crônicas examinadas diz respeito às redes textuais nas quais os autores se introduzem, com seus livros. Antonio da Piedade, no prólogo do Espelho de penitentes, dirige-se aos leitores fornecen-

${ }^{40}$ Lowe, Nuns' chronicles and convent culture in Renaissance and Counter-Reformation Italy, p. 28. Gabriella Zarri observa que, em geral, nos primeiros séculos do período moderno, os escritos de freiras eram dirigidos primordialmente ao seu círculo, no interior do convento ou da ordem. Gabriella Zarri, "Religious and devotional writing, 1400-1600", in Letizia Panizza e Sharon Wood (org.), A history of women's writing in Italy, Cambridge, Cambridge University Press, 2000, p. 79-92, p. 89.

${ }^{41}$ Neste caso especificamente, o frade recomenda também que a obra jamais fosse emprestada para alguém "de fora".

${ }^{42}$ Benta do Ceo, Jardim do ceo, p. 189. 
do coordenadas de localização da sua obra no conjunto das crônicas escritas sobre a província. No tocante à de autoria do frei Luiz da Ascenção, conforme já foi observado, aponta o caráter confuso, "na variedade das doutrinas, que lhe[s] aggregou [...] na multiplicidade de estranhos exemplos [...] e na digressão de alheyas materias". Sobre a de João de Brito e Mello, composta em cerca de 1680, diz que este autor "ainda que mostrava saber as regras de Historiador eloquente", por ser leigo não conhecia bem as regras da ordem, e assim "fallava como estranho". Outra tentativa, do frei Francisco da Cruz, teria ficado incompleta. Antonio da Piedade se posiciona também no interior da tradição clássica, em particular de escrita da história, citando autores como Horácio, Cícero, Tito Lívio e Políbio, além das já mencionadas concepções sobre o fazer histórico. Ao longo do texto, aparecem nas margens referências a obras e outros documentos dos quais certas ideias teriam se originado. Tais dispositivos estão ausentes no texto de Maria Benta do Ceo, com exceção dos autores citados no capítulo XXX da crônica, referido anteriormente, que versa sobre a Imaculada Conceição.

Diferenças ainda mais marcadas que as entre as crônicas examinadas acima há entre memórias de conventos de autoria feminina e masculina, escritas aproximadamente um século antes. Nas "Declarações importantes" aos leitores, no início da primeira parte da Historia Serafica da Ordem dos Frades Menores de S. Francisco na Provincia de Portvgal (1656), frei Manoel da Esperança também se posiciona numa rede textual, inicialmente relacionando sua obra com anais e uma crônica escritos anteriormente. Conquanto qualifique as obras, respectivamente dos freis Lucas Wadingo e Marcos de Lisboa, como "duas notaveis estatuas", observa que o primeiro, escrevendo quando já transferido para Roma, "não teve [o] que escrever" além de notícias retiradas de outro livro (do Padre Gonzaga), "todas curtas, \& viciadas alguãs”, e das bulas apostólicas relativas à ordem. Critica o segundo, frei Marcos de Lisboa, por não tratar das fundações, por ter se ocupado com "referir sãtidades" de toda a ordem e "querendo acodir ao commum cortou de necessidade por muitos particulares". Além disto, nota que o frade termina seu relato poucos anos antes de 1520. Destes problemas, teria resultado que a província encontravase numa situação de "esquecimento". Como Antonio da Piedade, Manoel da Esperança estabelece vínculos com a tradição erudita, mas mantém-se principalmente, embora não exclusivamente, no interior do universo de discussão teológica, citando doutores cristãos, legislação eclesiástica e passagens 
bíblicas. ${ }^{43}$ Incluem-se também na rede textual com que se relaciona as fontes escritas, que afirma ter coletado em um grande número de acervos cuja lista se estende desde todos os cartórios da Província de Portugal e da de Santo Antônio e "muitos" das províncias da Piedade, dos Algarves e da Arrábida, até os arquivos da Mesa de Consciência, do Reino, da Câmara de Lisboa e do Porto. Esperança lista ainda, entre suas fontes, uma diversidade de livros impressos e manuscritos.

É a partir deste "cabedal" que o autor afirma ter construído sua Historia, designação que ele declara ter escolhido "por ficar com liberdade de não ir despedaçando por muitos annos noticias, que convem andarem juntas". A concepção das diferenças entre anais, crônica e história, expressa neste texto, é mais próxima do modo como estas formas de relato histórico são entendidas tradicionalmente. E de fato o tratado de Esperança é, entre os estudados, o que mais se aproxima de uma síntese interpretativa da ordem, em lugar de constituir um conjunto de relatos acompanhando a cronologia. Inicialmente, em dez "Preluidios fundamentaes", dá ao leitor informações gerais sobre o ramo franciscano como um todo, desde o perfil e as ações do fundador até os diferentes desdobramentos do ramo em províncias e ordens, nas diversas regiões do mundo. Nas duas partes da Historia de sua autoria - a primeira e a segunda (esta última publicada em 1666) - ao tratar das casas monásticas, dá ênfase especial a aspectos como a reforma observante em casas que antes seguiam regra conventual, e a episódios referentes a sua relação com o contexto no interior e fora da Igreja.

Os dois volumes que complementam a obra do frei Manoel da Esperança foram escritos por outro frade, Fernando da Soledade, e publicados respectivamente em 1705 e 1709, com título ligeiramente diferente - Historia Serafica Cronologica da Ordem de S. Francisco na Provincia de Portugal. ${ }^{44}$ No proêmio dirigido aos leitores ${ }^{45}$ uma vez mais se observa o esforço do autor de localização do trabalho num universo de textos, incluindo os volumes iniciais da Historia, documentos dos arquivos de conventos da província, assim como

\footnotetext{
${ }^{43}$ Isto se explica, ao menos em parte, pelo fato de o autor ser leitor em Teologia, conforme informação no frontispício e nos pareceres de aprovação da Historia.

${ }^{44}$ Fernando da Soledade, Historia Serafica Cronologica da Ordem de S. Francisco na Provincia de Portugal, Lisboa, Oficina de Manoel e Joseph Lopes Ferreyra, 2 vols., 1705 e 1709, respectivamente.

${ }^{45} \mathrm{O}$ título completo - "Ao leytor devoto, particularmente aos religiosos da santa Província de Portugal" - sugere que estes últimos ocupavam lugar especial no público ao qual a obra era dirigida.
} 
memórias escritas por outros religiosos, cuja veracidade ele declara ter investigado. Soledade diz ter composto seu texto "pelo mesmo methodo" de Manoel da Esperança, porém acrescentando aspectos que "o fazem mais agradavel, \& comprehensivel". Um desses aspectos é o fato de ter indicado, nas margens, os anos a propósito dos quais escreve, o que serve de justificativa para a adição da designação "cronológica" ao título. Em verdade, ao longo do texto, a referência às datas é lacunar e imprecisa. Uma vez mais está presente o diálogo com a cultura letrada, eclesiástica e laica, com o proêmio entremeado de citações e sentenças em latim e trazendo em anexo elogio, em verso latino, de suposta autoria do frei Inácio de Santa Maria. Parágrafos numerados sugerem uma orientação do texto para a consulta e leitura individual.

Os capítulos XII-XVI do Tomo III, e XVIII-XXIII do Tomo IV tratam respectivamente dos conventos femininos observantes de Jesus de Setúbal e da Madre de Deus de Lisboa. Ambos os conventos, nos seus primeiros tempos, pertenciam à Província de Portugal, tendo sido mais tarde incorporados à dos Algarves, quando esta foi criada, em $1533 .{ }^{46}$ Estas passagens da Historia Serafica Cronologica da Ordem de S. Francisco na Provincia de Portugal são particularmente relevantes, por permitirem uma comparação entre as formas narrativas de Fernando da Soledade e das autoras de duas obras versando sobre a memória destas casas. As obras, manuscritas, foram compostas na primeira metade do século XVII, por religiosas ali ingressadas. São elas o Tratado da antiga e coriosa fundaçaõ do Convento de Jesus de Setuval [...], da Madre Leonor de São João (que teve sua primeira versão acabada em 1630, mas que inclui registros datados até 1646), e a Noticia da fondação do Convento da Madre de Deos das religiozas descalças de Lisboa [...], atribuída a Maria do Sacramento (produzida entre 1639 e 1652). ${ }^{47}$

O tratado sobre o convento de Setúbal compõe-se de cinco partes, as quais discorrem sobre os episódios em torno da sua fundação (Primeira par-

\footnotetext{
${ }^{46}$ Soledade, Historia Serafica Cronologica da Ordem de S. Francisco [...], 1709, p. 79.

${ }^{47}$ Maria do Sacramento, Noticia da fundação do Convento da Madre de Deos das religiozas descalças de Lisboa, da primeira regra de nossa Madre Santa Clara [...], Lisboa, 1639, [MS]. Diogo Barbosa Machado, na compilação de autores portugueses que produziu no século XVIII, aponta Maria do Sacramento, que habitou a casa entre 1623 e 1679, como autora da obra. Estudo mais recente, feito por Ivo Carneiro de Souza, propõe que a Noticia tem autoria tripla, de Catarina das Chagas, Joanna da Piedade e Margarida da Trindade. Diogo Barbosa Machado, Biblioteca Lusitana histórica, crítica e cronológica, $2^{\mathrm{a}}$ ed., Lisboa, Academia Real da História Portuguesa, 1930-1934, 4 vols., tomo 3, p. 423; Ivo Carneiro de Souza, Rainha D. Leonor (1458-1525). Poder, misericórdia, religiosidade e espiritualidade no Portugal do Renascimento, Lisboa, Calouste Gulbenkian, 2002, p. 499-500.
} 
te), os ritos e práticas determinados pelas regras no dia a dia no interior do mosteiro (Segunda parte), as relíquias e outras "coisas notáveis" existentes na casa (Terceira parte), as vidas exemplares de religiosas (Quarta parte) e ocorrências relevantes durante os abadessados (Quinta parte). Em que pese esta estrutura indicar um ordenamento prévio da escrita, este se dilui, no final, com a inclusão de alguns capítulos que não estavam previstos inicialmente, ${ }^{48}$ contendo diversas matérias, além de cópia de licença concedida para impressão do livro (datada de 1646) e de inventário dos feitos do ramo franciscano. Este inclui desde os diferentes lugares do mundo em que seus membros atuavam até indivíduos oriundos da aristocracia que nele ingressaram, passando pelo número de conventos, províncias, membros beatificados e ocupantes da alta hierarquia da Igreja. Trata-se, desta forma, de uma obra aberta, que podia receber acrescentamentos posteriores, característica possibilitada pela forma manuscrita.

A Noticia da fundação do Convento da Madre de Deos tem formato peculiar, se comparado aos demais textos aqui analisados: foi composta na forma de diálogo. A autora da Noticia como um todo, ou a que escreveu a parte inicial da obra, declara que teria reproduzido conversas de fato havidas entre as sórores em encontros no período do Natal de 1638, chamados fogueiras. A par da menção ao ano há, no texto, outros dispositivos que produzem efeito de verdade, como a referência ao local onde as fogueiras teriam ocorrido e ao fato de que nem todas as religiosas do mosteiro haviam delas participado, por muitas estarem doentes. Ainda que, à primeira vista, não fique evidente um plano geral do escrito, é possível detectar certo ordenamento temático que o aproxima do Tratado sobre o Convento de Jesus de Setúbal. ${ }^{49}$ Além deste aspecto, observa-se que a extensão dos diálogos que compõem os capítulos, em particular a dos quatro primeiros e do último, é bastante homogênea (23-25 fólios manuscritos). É dito no texto que as conversas narradas no penúltimo e último capítulos tiveram lugar em outros anos, 1644 e 1652, respectivamente. Se isto de fato ocorreu, a Noticia, assim como o Tratado de Leonor de São João, constitui exemplo de obra aberta.

As autoras de ambas as memórias de conventos fazem referência a fontes escritas, depositadas nos seus arquivos, que elas teriam consultado. A não

\footnotetext{
${ }^{48} \mathrm{O}$ índice lista até o capítulo XVII da Quinta parte, que trata do abadessado da própria autora, durante o qual ela afirma que concluiu o livro. Este abadessado teria se encerrado em 1631, mas os registros adicionais incluem notícias relativas a até 1641 .

${ }^{49}$ Pacheco, "Quando as freiras faziam história [...]", p. 6.
} 
ser isto, não procuram entrar em diálogo com outros autores ou se posicionar em relação a eles. E a monja que compôs a parte inicial da Noticia enfatiza a importância do que era contado pelas religiosas, passado de boca a ouvido de uma geração para outra. Chega mesmo a afirmar que "ainda que no Archivo haja alguns papeis, q de tudo daõ noticia, naõ he em forma que possamos ver quando queremos". ${ }^{50}$ Por outro lado, é relevante notar a existência, nas memórias, de trechos cuja forma sugere principalmente uma apropriação por meio da consulta e leitura silenciosas. Um exemplo é o capítulo XXXI da Segunda parte do Tratado, que consiste em uma lista dos nomes dos confessores do convento, à qual foram adicionadas cópias de cartas "de edificação, e antigas" - do frei Henrique de Coimbra, o primeiro confessor, à primeira abadessa, sóror Colleta (s/d); e da abadessa do Convento da Veronica de Valença, Clara Berbegal, à abadessa de Setúbal (1499). ${ }^{51}$

Outros elementos remetem a uma associação mais estreita dos textos clarianos com um universo em que a oralidade tinha papel central. Uma comparação dos relatos do frei Fernando da Soledade e da madre Leonor de São João sobre os começos do mosteiro de Setúbal evidencia que, embora ambos tenham sido compostos em linguagem ornamentada, entremeada de declarações de personagens - o que indica que o do frei também podia ser dirigido para a leitura em voz alta, em comunidade,$-{ }^{52}$ este é por vezes interrompido para discutir, com base em textos citados nas margens, questões sobre as quais haveria polêmica. Constituem exemplo disto as discussões sobre o lugar de origem da fundadora Justa Rodrigues e sobre as razões pelas quais freiras francesas se transferiram para Valença, na Espanha, de onde algumas foram para Portugal fundar o mosteiro. ${ }^{53} \mathrm{~A}$ abordagem mais analítica de Soledade é também ilustrada pela passagem em que discorre sobre as relíquias da casa, por ele introduzida com o paradoxo de "sendo muyto grande o resplendor da Pobresa Serafica neste santo Mosteyro", o mesmo "logra[r] pacificamente hum ${ }^{50}$ Sacramento, Noticia da fondação do Convento da Madre de Deos [...], fol. 2r.

${ }^{51}$ São João, Tratado da antiga e coriosa fundaçaõ do Convento de Jesus de Setuval [...], fol. 139v148 r.

${ }^{52}$ Lowe (2003, p. 30-32) interpreta a citação direta das falas de personagens, em primeiro lugar, como um mecanismo usado para oferecer evidências que comprovariam a veracidade de uma história relatada. Além disto, segundo ela, a citação direta das falas remete à forma oral pela qual as autoras estudadas teriam obtido as informações que registraram. Lowe nota ainda que este tipo de narração é uma ferramenta útil para acentuar a tensão dramática em momentos como os em que as autoras fazem referência a visões experimentadas pelas religiosas, e que, desta forma, "aumentava a possibilidade de participação da audiência".

${ }_{53}$ Soledade, Historia Serafica Cronologica da Ordem de S. Francisco [...], 1705, p. 424 e $428-$ 429 , respectivamente. 
thesouro de inestimavel preciosidade". ${ }^{44}$ Nos capítulos correspondentes do seu tratado, Leonor de São João simplesmente faz menção às características e origem das relíquias, enfatizando seu enorme valor. ${ }^{55}$ Quer tenham recorrido ou não às mesmas fontes, a história narrada pela madre silencia sobre assuntos supostamente não elevados, em especial como tema de conversação coletiva, como infestações de baratas e piolhos de que o mosteiro teria sido vítima, ainda que estes tenham sido referidos por Soledade para ilustrar "beneficios do Ceo" na extinção das pragas. ${ }^{56}$

O texto de Fernando da Soledade, em que este autor trata do mosteiro da Madre de Deus, é mais linearmente descritivo que a passagem em que aborda o convento de Setúbal. Discorre sobre episódios relativos à fundação, sobre a estreita relação da casa com a aristocracia portuguesa, as importantes relíquias do mosteiro e religiosas que se destacaram por suas virtudes. Se nos capítulos iniciais o texto se adequaria bem a uma leitura oralizada, na parte final torna-se apressado, quase uma listagem do que restava para ser registrado.

Na Noticia, o enquadramento dos assuntos tratados é a experiência humana imediata. Um exemplo ilustrativo é a "Pratica segunda, na primeira oitava do Natal", em que o tema central abordado é a regra da casa, explorada na forma do relato, pelas irmãs participantes do diálogo, das maneiras como lidavam com rigores como penitências, restrições alimentares, o desconforto decorrente das vestimentas e trabalhos humildes. ${ }^{57}$ Verifica-se, nos diálogos, o tom agonístico e fundado na empatia, e a teatralidade das falas de diversas personagens na primeira pessoa. Cada uma das "Praticas" examina temas edificantes através de modos simplificados de intriga, que poderiam ser lidos em voz alta, por uma ou mais narradoras, em intervalo de tempo compatível com o de um encontro comunitário.

Retornando, para concluir, ao problema do significado dos diferentes usos e tipos de escritura, pode-se associá-los à delimitação de espaços distintos de atuação de homens e mulheres, no universo católico. A escrita elaborada mais de acordo com modos de pensamento e expressão característicos de culturas letradas estaria vinculada aos primeiros, aos quais a Igreja facultava uma educação mais extensiva e o direito de explorar e enunciar questões

${ }^{54}$ Soledade, Historia Serafica Cronologica da Ordem de S. Francisco [...], 1705, p. 438.

${ }^{55}$ São João, Tratado da antiga e coriosa fundação do Convento de Jesus de Setuval [...], fol. 149v179r. Ambos os textos fazem menção a um pedaço do Santo Lenho e a ossos dos apóstolos, entre as inúmeras relíquias depositadas no convento.

${ }^{56}$ Soledade, Historia Serafica Cronologica da Ordem de S. Francisco [...], 1705, p. 441-442.

${ }^{57}$ Sacramento, Noticia da fondação do Convēto da Madre de Deos [...], fol. 27v-53v. 
teológicas e legais. Escritas mais "orais" seriam predominantes na esfera monástica feminina. Tais associações podem, num primeiro momento, ser interpretadas simplesmente como expressão do binômio poder masculinosubmissão feminina. Mas é importante ter em conta que, como argumenta Antonio Castillo Gómez, o recurso à palavra falada como veículo central de comunicação permitia às mulheres escaparem do controle de confessores, diretores espirituais e outras autoridades, o que se deduz das freqüentes orientações, por estes, de que mulheres registrassem por escrito suas revelações, conhecimentos e experiências. ${ }^{58} \mathrm{O}$ vigor da oralidade, desta forma, pode significar uma maior autonomia feminina na ordem sócio-simbólica do período. ${ }^{59}$ No domínio predominantemente letrado e masculino, na formulação do frei Fernando da Soledade a propósito da fundadora do Convento de Setúbal, "não se esperava [...] tanto alento, nem tão alto espirito de hum sexo tão debil", ${ }^{60}$ expressão que é repetida pelo frade com respeito às monjas do Convento da Madre de Deus. ${ }^{61}$ Uma concepção bem distinta da veiculada em poemas reproduzidos nas páginas iniciais do Tratado de Leonor de São João, atribuídos a "hum religiozo da Ordem dos Pregadores" cujo nome não é mencionado, o que parece ser um mecanismo para conferir autoridade a composições da própria autora ou de suas companheiras de claustro. Num desses poemas, um soneto em homenagem à mesma fundadora, são inclusive mencionadas diversas mulheres da história e mitologia antigas, que se notabilizaram por sua força ${ }^{62}$ A vivência comunitária no interior dos mosteiros, incluindo rituais em que se praticava a "boa conversação", isolada, ao menos em parte, de um entorno hostil ao elemento feminino, possivelmente ensejava uma representação bem mais positiva das suas potencialidades.

\footnotetext{
${ }^{58}$ Antonio Castillo Gómez, "Ler en comunidad. Libro y espiritualidad en la España del Barroco", Via Spiritus, 7, 2000, p. 99-122, p. 109-110.

${ }^{59}$ Também a não publicação de um texto em versão impressa, com sua permanência em forma manuscrita, parece ter representado uma maior proteção em relação à vigilância da Igreja e do Estado, os quais direcionavam sua atenção principalmente para as casas tipográficas. Fernando Bouza-Álvarez, "Cultura escrita e história do livro - a circulação manuscrita nos séculos XVI e XVII", Leituras: Revista da Biblioteca Nacional de Lisboa, Série 3, $n^{\circ}$. 9/10, Outubro 2001-Outubro 2002, p. 63-95, p. 81.

${ }^{60}$ Soledade, Historia Serafica Cronologica da Ordem de S. Francisco [...], 1705, p. 424.

${ }^{61}$ Soledade, Historia Serafica Cronologica da Ordem de S. Francisco [...], 1709, p. 72.

${ }^{62}$ Esta evidência, assim como o diálogo com a tradição clássica estabelecido por alguns dos autores investigados, contradiz a proposição de Lowe de que, pelo final do século XVI, a Contra-reforma tinha conseguido extinguir completamente as influências clássicas no meio monástico. Lowe, Nuns' chronicles and convent culture in Renaissance and Counter-Reformation Italy, p. 45 .
} 